\title{
Evaluation the inhibitory action of Egyptian honey from various sources on fungal and bacterial growth and aflatoxins production
}

\author{
Amal A.I. Mekawey \\ The Regional Center for Mycology and Biotechnology- Al-Azhar University, \\ Cairo, Egypt
}

\begin{abstract}
Serial concentrations of three unprocessed honey (mountain; nuwara clover and citrus) samples from Egypt, were evaluated for their ability to act as antimicrobial activity against fifteen fungal species including toxigenic strains of Aspergillus flavus and $A$. parasiticus and four Gram positive and five Gram negative pathogenic bacterial isolates. Also, investigation of inhibitory action of aflatoxins production by $A$. flavus and $A$. parasiticus was studied. $90 \%$ and $100 \%$ concentrations of three honeys used, exhibited high ability to inhibit the growth of most of fungal and bacterial isolates. Mountain honey was the best honey. It showed antimicrobial activity followed by citrus then nuwara clover honey. However, $80 \%$ concentration from only mountain honey showed antimicrobial activity while all other honey concentrations prepared did not show any ability to reduce the growth of all fungal and bacterial isolates tested. As well as, no aflatoxins were produced at $100 \%$ concentration of three honeys used, while great reduction of aflatoxins production was detected after treatment with $90 \%$ concentration of all honeys. Moderated effect on toxins production was reported by $80 \%$ concentration and little inhibition was obtained at $70 \%$ honey concentration. Other honey concentrations (10\% to 60\%) showed opposite effect on aflatoxins production, where the amounts of toxins were increased. Mountain honey was the best, which showed ability to inhibit the production of aflatoxins by both of A. flavus and $A$. parasiticus followed by nuwara clover then citrus honey.
\end{abstract}

Key words: Honey, Apis mellifera lamarkii, Antimicrobial activity, Aflatoxin production.

\section{INTRODUCTION}

Honey is a natural food product, rich in essenial nutrients, a saturated solution of sugar (carbhydrates) made by bees that collect nectar, which is a liquid secretion from flowers. The honey bees take this nectar back to their hives where they add enzymes to it and place it in wax cells called honeycombs, some of the most important honey enzymes are invertase, diastase, and glucose oxidase. This is where it ripens to form honey. During the ripening process, the enzymes convert sucrose into monosaccharides glucose and fructose. There are many different types of honey. The differences are predicated on the floral source (Wahdan, 1998).

Honey was first known historically as a flavored sweetening agent. Its use dates back to ancient times, with Egyptian medical texts (c. between 2600 and 2200 BC) mentioning honey in at least 900 remedies. Almost all early cultures universally hailed honey for its sweetening and nutritional qualities, as well as its topical healing properties especially for skin diseases, sores, wounds, and skin ulcers. During war time it was used on wounds as an antiseptic by the ancient Egyptians, Asyrians, Greeks, Romans, Chinese, and even by the Germans as late as World War I (Subrahmanyam, 1991).

For thousands of years honey has been popular for its therapeutic properties since ancient times for "disorders" ranging from baldness to gastrointestinal distress. Due to its quality, it is used by human beings as food and as medicine for the treatment of various diseases such as infected surgical wounds, decubitus ulcers, 
Amal A.I. Mekawey

skin grafting and surgical debridement, rapid suppression of inflammation, gastritis, upset stomach, sore throat, esophageal ulcer, cure diarrhea and treat asthma. Among the most common uses of stingless bee honey are to treat cough, tonsillitis and intestinal ulcers, cold, disease of the mouth, mucus membrane, and as treatment of Helicobacter pylori (Bang et al., 2003). Researchers are not absolutely sure why honey heals but they are learning new things about honey every day. Honey contains a variety of sugars and minerals and it is considered as an antioxidant. This means that it allows the blood to circulate better and provide more oxygen to areas of the body such as the brain. It has even been shown to be low in calories and useful as a sweetener for diabetics, people with heart disease (Molan, 2006).

Honey has been shown to have wounds healing properties, which can be ascribed to its antimicrobial activity (burn wound is an ideal substrate for bacterial growth). The antimicrobial activity can be effective against a broad spectrum of bacterial species especially those of medical importance. Nonetheless, concerns regarding antibiotic resistance and renewed interest in "natural" remedies has promoted a resurgence of interest in the an-timicrobial and wound healing properties of honey. If you think about it, bees would not have been able to survive for millions of years without evolving a method of preserving their food from fermentation and spoilage by microorganisms (Ijaz et al 2008).

Honey's antimicrobial activity has been attributed to osmolarity, hydrogen peroxide determined by relative levels of glucose oxidase and catalase, acidity (honey is characteristically quite acidic; its $\mathrm{pH}$ is between 3.2 and 4.5, which is low enough to be inhibitory to many pathogens). So, in undiluted honey, the acidity is a significant antibacterial fac-tor. The non-peroxide factors contributing to honey antimicrobial and antioxidant activity are the lysozyme, aromatic, phenolic compounds and flavnoids. Taken as a whole, these factors give honey great potency to use for medical purposes (Cooper et al 1999).

Composition of Honey according to (Molan, 2006) are water (17.20\%); Sugars (79.59\%) [Fructose (38.19\%); Glucose (31.28\%); Sucrose (1.31\%) Maltose and other reducing disaccharides (7.31\%); Higher sugars (1.5\%)]; Acids $(0.57 \%)$ (gluconic, citric, malic, succinic, formic, acetic, butyric, lactic, pyroglutamic and amino acids); Proteins (0.26\%); Ash $(0.17 \%)$ (Minerals: potassium, sodium, calcium, magnesium, chlorides, sulfates, phosphates, silicia, etc.). Enzymes (2.21\%) such as invertase (converts sucrose to dextrose and levulose); diastase (converts starch to dextrins); glucose oxidase (converts dextrose to gluconolac-tone); catalase (de-composes hydrogen peroxide); phosphatase (decomposes glycerophosphate).

The honey phenolic compounds are the phenolic acids and flavonoids, which are considered potential markers of the honey botanical origin. The phenolic acids are divided in two subclasses: the substituted benzoic acids and cinnamic acids. The flavonoids present in honey are divided in three classes with similar structure: flavonols, flavones and flavanones. These are important due to their contribution to honey colour, taste and flavour and also due to their beneficial effects on health. These compounds are reported to exhibit anticarcinogenic, antiinflammatory, antiatherogenic, anti-thrombotic, immune modulating and analgesic activities, among others and exert these functions as antioxidants (Muli et al 2008).

In the 1960 more than 100,000 young turkeys on poultry farms in England died in the course of a few months from an apparently new disease that was termed "Turkey X disease". It was soon found that the difficulty was not limited to turkeys. Ducklings and young pheasants were also affected and heavy mortality was 


\section{Evaluation the inhibitory action of Egyptian honey from various sources on fungal and bacterial growth and aflatoxins production}

experienced. A careful survey of the early outbreaks showed that they were all associated with feeds, namely Brazilian peanut meal. An intensive investigation of the suspect peanut meal was undertaken and it was quickly found that this peanut meal was highly toxic to poultry and ducklings with symptoms typical of Turkey X disease (Efem, 1988).

Two fungus Aspergillus flavus and A. parasiti-cus have a worldwide matter. These fungi readily colonize several important crops such as corn, cottonseed, peanuts, and tree nuts. Most of A. flavus and $A$. parasiticus can produce polypeptide derived secondary metabolites called aflatoxins, which are highly toxic, mutagenic and carcinogenic to human and animals. High level of aflatoxin exposure produces an acute hepatic necrosis, resulting later in cirrhosis, and/or carcinoma of the liver. Acute hepatic failure is made manifest by hemorrhage, edema, alteration in digestion, and absorption and/or metabolism of nutrients and mental changes and/or coma (Accinelli et al. 2008). No animal species is immune to the acute toxic effects of aflatoxins including humans; however, humans have an extra- ordinarily high tolerance for aflatoxin exposure and rarely succumb to acute aflatoxicosis. Children, however, are particularly affected by aflatoxin exposure which leads to stunted growth and delayed development. Chronic exposure also leads to a high risk of developing liver cancer, as aflatoxin metabolite can intercalate into DNA and alkylate the bases through its epoxide moiety (Peterson et al 2006).

So, the purpose of the present study was to in-vestigate the antimicrobial activity of three Egyptian raw honeys against fifteen pathogenic fungal isolates; four Gram positive and five Gram negative bacterial isolates and to evaluate their effect on stability and production of aflatoxins by Aspergillus flavus and $A$. parasiticus at different concen-trations.
MATERIALS AND METHODS

\section{Sampling procedure}

Three multifloral honey samples (mountain; nuwara clover and citrus) which were extracted from Egyptian bees (Apis mellifera lamarkii) and obtained at the retail public markets, in the Abbassya city, Cairo, Egypt, were used to investigate their activity as antifungal; antibacterial and as inhibitor of aflatoxins production agents. All pack-aged samples (200 g) were transported and stored at room temperatures $\left(20^{\circ} \mathrm{C}\right)$.

\section{Test Organisms}

Fifteen fungal isolates and nine bacterial iso-lates (four Gram positive and five Gram negative), which were employed for this investigation are listed in Table (1). All filamentous fungal strains were kindly provided from culture collection of the Regional Center for Mycology and Biotechnology (RCMB), Al-Azhar University, while bacterial and yeasts isolates were provided from culture collec-tion of the El-Demerdash Hospital.

\section{Antimicrobial Assays}

Antimicrobial potentialities were expressed as the diameter of inhibition zones; agar well diffusion method was used. Seven $(1 \mathrm{~cm}$ diameter) holes were made in agar media by sterile cork borer using sterile plates $(15 \times 15 \mathrm{~cm})$, which had previously been seeded with test isolates, then filled by $100 \mu \mathrm{L}$ with each honey concentrations. The concentrations of honey made with the sterile distilled water varied from 10 to $100 \%$. Specifically, the concentrations had the following percentages of honey by volume: $100 \%, 90 \%, 80 \%, 70 \%, 60 \%$, $50 \%, 40 \%, 30 \%, 20 \%$ and $10 \%$. Plates were left in a cooled incubator at $4( \pm 2){ }^{\circ} \mathrm{C}$ for one hour and then incubated at $37( \pm 2)$ ${ }^{\circ} \mathrm{C}$ (Abde- Kader and Seddkey, 1995). Inhibition zones developed due to active seed ingredients were measured after 24 48 hours of incubation time. 
Amal A.I. Mekawey

\section{Extraction of aflatoxins}

Inoculation of $1 \mathrm{ml}$ spore suspension $\left(10^{4}\right.$ cells $\left./ \mathrm{ml}\right)$ of each of Aspergillus flavus or A. parasiticus in 250 $\mathrm{ml}$ Erlenmeyer flasks each containing 100 $\mathrm{ml}$ of sterile YES broth medium mixed with each honey type to gave finally serial concentration from honey $(10,20,30,40$, $50,60,70,80,90,100 \%)$. Three replicates for each concentration were prepared and incubated at $25( \pm 2)^{\circ} \mathrm{C}$ for 21 days. The broth filtrates were mixed with an equal volume of chloroform in a separating funnel. The residue was re-extracted twice for complete extraction. The chloroform extract was defatted with hexane for separate lipid layer, concentrated in a rotary evaporator. The residues were reconstituted in $1 \mathrm{ml}$ methanol for further HPLC chromatographic analysis (Hermínia et al 2003).

\section{Determination of aflatoxins B1, B2, G1and G2 by HPLC}

The samples were analysed for the quantification of aflatoxins using immunoaffinity columns supplied from Rhône -diagnostics technologies Ltd (Spain), and quantified by high performance liquid chromatography (HPLC) according to the method described by Stroka et al (2000), with modifications an in the initial extraction phase. The solvent mixture was water: methanol $(8: 2)$ instead of methanol : water $(8: 2, \mathrm{v} / \mathrm{v})$. The sample extract was filtered, diluted and applied in an immunoaffinity column containing antibodies specific to aflatoxins B1, B2, G1 and G2. Standard aflatoxins (AF) B1, B2, G1 and G2 were purchased from Sigma-Aldrich (Ref.A-6636, A-9887, A-0138 and A-0263 respectively) (Quimica S.A.Spain). The stock solution, working standards and the calibration curve were prepared and determined as described by Stroka et al. (2000).

\section{RESULTS AND DISCUSSION A-Antimicrobial Activities}

With the irrational and massive use of antibiotics in underdeveloped and developing countries, resultantly there was increased resistance to antibiotics and with the increased interest in herbal medicine and use of honey for various therapeutic purposes has led to the search for new antibacterial and antifungal honey. Hence a present study is conducted to assess the antibacterial and fungicidal activity of three honey locally produced under natural and farm environment in Egypt.

In vitro antifungal and antibacterial activities of serial concentrations of three kinds of Egyptian raw honey were investigated. $10 \%$ to $70 \%$ concentra-0tion of all honey types used did not show ability to reduce any of tested bacterial or fungal growth. Eighty percentage concentration from only mountain honey inhibit the growth of some of fungal and bacterial isolates, where A. fumigatus; P. chrysoge-num; Ca. krusei and $\mathrm{Ca}$. dubliniensis only reduced their growth by $1.6 ; 1.0 ; 1.2$ and $1.5 \mathrm{~cm}$ inhibition zones, respectively. Also, St. pneumonia and $B$. subtilis only bacterial isolated affected by 1.5 and $2.0 \mathrm{~cm}$ inhibition zones, respectively.

These results may be agree with those of obtained by Ugur et al. (2000) who declared that, great antibacterial and antifungal activities were reported when examined the effects of honey samples on three Escherichia coli and two Staphylococcus aureus strains that are multires-istant to antibiotics and on $S a$. typhimurium, Br. abortus, Pr. mirabilis, Str. pyogenes, B. cereus, Ca. tropicalis, and $A$. niger in vitro. Also, Irish et al (2006) evaluated the ability of honey samples from different floral sources to inhibit the growth of 40 yeast strains $(C$. albicans, C. krusei, C. glabrata and $T r$. spp.) at different concentrations ranging from $20-80 \%$ (v/v). Little or no antifungal activity was seen at honey concentrations $<20 \%$, also, these honey had antifungal 


\section{Evaluation the inhibitory action of Egyptian honey from various sources on fungal and bacterial growth and aflatoxins production}

activity at the high concentration of $80 \%$ (v/v). Basson et al. (2008) who evaluated the antimicrobial activity of different honey samples, high inhibitory effect on Gram positive bacteria were recorded compared to all other Gram negative and fungal species. Pure honey was more effective in inhibiting bacterial growth than different dilutions.

Results in Table (1) reveal that all fungi and bacteria used were highly susceptible to mountain honey at $90 \%$ and $100 \%$ concentrations but at different degrees. Many of reports confirm the present results such as Kwakman et al. (2008) who reported that raw honey is effective against fungi such as $C a$. albicans and $A$. niger and against antibiotic resistant bacteria such as methicillin resistant St. aureus. Also, Brady et al. (2004) suggested that, to assess the variation in antibacterial and antifungal activity of unifloral honey samples obtained from commercial beekeepers. The honey was tested against St. aureus, E. coli, Ca. albicans and the dermatophyte T. mentagrophytes. Antifungal activity of samples increased with increasing sample concentrations.

The present results revealed that inhibition of growth depends on the type and concentration of honey as well as the test pathogen. The possible mechanism of causes of the antimicrobial action of honey is most likely a combination of a number of different factors. Its low water activity is likely to play a major role when honey is applied topically. Sugar syrups resembling honey in its high sugar content was made shown that honey have superior activity. Hydrogen peroxide is not the only inhibine in honey. In fact, inhibines in honey include a wide range of many other substances, many of which have not been identified. Two important classes of these inhibines are the flavonoids and the phenolic acids. Flavonoids and two phenolic acids (caffeic acid and ferulic acid) were extracted by Wahdan (1998).

\section{B-Aflatoxins Production}

Aspergillus flavus typically produces aflatoxins (B1 and B2), whereas A. parasiticus produce afla-toxins (G1, G2, B1 and B2) (Accinelli et al. 2008). No aflatoxins were detected on all fungal metabolites treated with $100 \%$ concentration of the all honey used in this study, as well as, great re-duction of aflatoxins were detected in both of $A$. flavus and $A$. parasiticus extracts with $90 \%$ of the all honey while moderated effect on toxins produc-tion were reported by $80 \%$ concentration and little effect was obtained at $70 \%$ honey concentrationTable (2). No effect on aflatoxins production by two Aspergillus species extracts tested under serial concentration of honey used from $10 \%$ to $60 \%$, on contrast the level of toxins production increased.

The present results are on line with those re-ported by Mekky (2007) who studied that, un-processed honey was inoculated with toxigenic strains of Aspergillus flavus and A. parasiticus. The fungi grew and sporulated in varying amounts of honey diluted with water, but none of the cultures produced detectable levels of aflatoxin. Growth and subsequent sporulation were seen only in me-dia containing up to and including $60 \%$ of honey. Media having $40 \%$ of honey showed growth and sporulation by day two. Neither Aspergillus species produced toxins even in $10 \%$ honey.

Figure (1) reported that standards of aflatoxins were detected at certain retention times whereas AFB1; AFB2; AFG1 and AFG2 were detect at 11.65; 8.47; 17.42 and 14.32 minutes, respectively. All tested samples were detected at the same retention times but at different concentrations (Table 2). Figures $(2,3 \& 4)$ show the effect of mountain; nuwara clover and citrus honey on AFB1 and AFB2 produced by A. flavus, respectively at $70 \%, 80 \%$ and $90 \%$ concentrations while Figures $(5,6 \& 7)$ recorded the effect of mountain; nuwara 
Amal A.I. Mekawey

clover and citrus honey on AFB1; AFB2;

AFG1 and AFG2 produced by $A$. parasiticus, respectively at the same concentra-ions.

Table 1. In vitro antifungal and antibacterial activities of mountain; nuwara clover and citrus honeys at $80 \% ; 90 \%$ and $100 \%$ concentrations. Data are expressed as mean diameter of inhibition zone (cm); (A): Mountain Honey; (B): Nuwara clover Honey ; (C): Citrus Honey

\begin{tabular}{|c|c|c|c|c|c|c|c|c|c|}
\hline \multirow{2}{*}{$\begin{array}{l}\text { Concentrations } \\
\text { Microorganisms }\end{array}$} & \multicolumn{3}{|c|}{$80 \%$} & \multicolumn{3}{|c|}{$90 \%$} & \multicolumn{3}{|c|}{$100 \%$} \\
\hline & (A) & (B) & (C) & (A) & (B) & (C) & (A) & (B) & (C) \\
\hline \multicolumn{10}{|l|}{ Fungal isolates used } \\
\hline Aspergillus flavus & 00 & 00 & 00 & 3.5 & 00 & 1.5 & 2.7 & 1.7 & 00 \\
\hline Aspergillus parasiticus & 00 & 00 & 00 & 3.2 & 0.5 & 2.8 & 3.6 & 2.2 & 2.5 \\
\hline Aspergillus fumigatus & 1.6 & 00 & 00 & 2.5 & 2.0 & 2.2 & 2.0 & 2.0 & 1.5 \\
\hline Aspergillus niger & 00 & 00 & 00 & 3.8 & 2.0 & 2.8 & 3.0 & 2.5 & 2.8 \\
\hline \multicolumn{9}{|l|}{ Syncephalastrum } & 00 \\
\hline Penicillium chrysogenum & 1.0 & 00 & 00 & 3.4 & 2.0 & 2.5 & 4.0 & 1.5 & 2.5 \\
\hline Microsporum canis & 00 & 00 & 00 & 2.5 & 00 & 2.0 & 2.0 & 00 & 2.0 \\
\hline $\begin{array}{l}\text { Trichophyton } \\
\text { mentagrophytes }\end{array}$ & 00 & 00 & 00 & 2.2 & 00 & 00 & 1.8 & 1.0 & 2.0 \\
\hline Candida albicans & 00 & 00 & 00 & 3.5 & 00 & 3.0 & 3.5 & 00 & 2.5 \\
\hline Candida krusei & 1.2 & 00 & 00 & 3.0 & 00 & 2.6 & 3.0 & 0.5 & 2.0 \\
\hline Candida glabrata & 00 & 00 & 00 & 3.0 & 1.2 & 2.5 & 2.6 & 00 & 2.5 \\
\hline Candida dubliniensis & 1.5 & 00 & 00 & 3.3 & 2.2 & 2.0 & 3.5 & 2.5 & 2.0 \\
\hline Cryptococcus humicola & 00 & 00 & 00 & 3.5 & 00 & 2.6 & 3.9 & 1.0 & 2.8 \\
\hline Geotrichum candidum & 00 & 00 & 00 & 4.2 & 1.9 & 3.3 & 3.5 & 1.5 & 3.0 \\
\hline Trichosporon cutameum & 00 & 00 & 00 & 2.8 & 00 & 2.0 & 3.0 & 00 & 00 \\
\hline \multicolumn{10}{|l|}{ Bacterial isolates used } \\
\hline Staphylococcus aureus & 00 & 00 & 00 & 3.8 & 1.2 & 2.5 & 4.5 & 2.0 & 2.5 \\
\hline Streptococcus pneumonia & 1.5 & 00 & 00 & 3.5 & 2.0 & 3.5 & 4.0 & 2.5 & 3.7 \\
\hline Bacillus subtilis & 2.0 & 00 & 00 & 2.8 & 3.5 & 2.5 & 3.2 & 3.0 & 2.0 \\
\hline Bacillus thuringiensis & 00 & 00 & 00 & 2.7 & 1.2 & 0.9 & 2.7 & 2.0 & 2.0 \\
\hline Salmonella typhi & 00 & 00 & 00 & 2.3 & 0.5 & 2.0 & 2.0 & 1.1 & 1.0 \\
\hline Escherichia coli & 00 & 00 & 00 & 4.0 & 1.5 & 3.0 & 2.5 & 2.3 & 2.6 \\
\hline Pseudomonas aeruginosa & 00 & 00 & 00 & 1.2 & 00 & 00 & 1.5 & 0.9 & 0.5 \\
\hline Serratia marcescens & 00 & 00 & 00 & 3.5 & 3.0 & 2.5 & 2.0 & 3.4 & 1.0 \\
\hline Klebsiella pneumonia & 00 & 00 & 00 & 4.5 & 1.0 & 3.5 & 3.6 & 2.8 & 2.0 \\
\hline
\end{tabular}




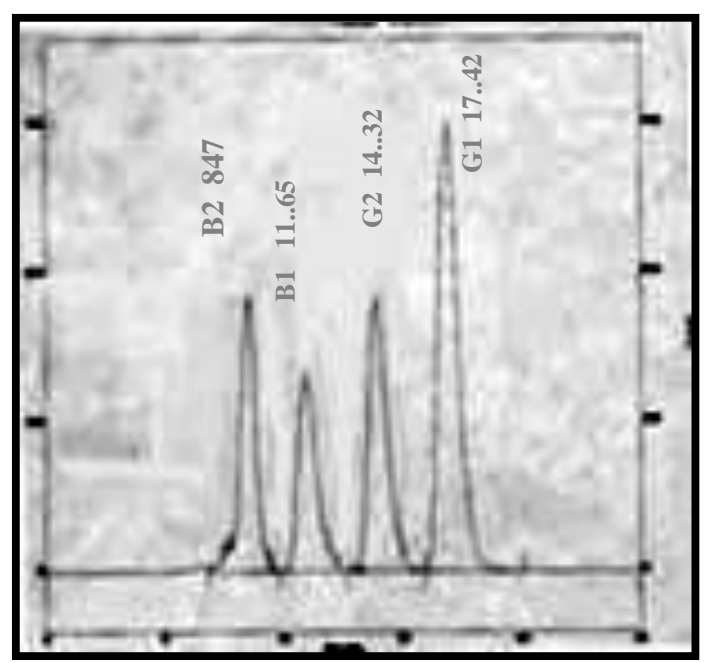

Figure 1. Photographic showed the retention times of standards of aflatoxins (AFB1; AFB2; AFG1; AFG2)

Table 2. Effect of honey at $70 \% ; 80 \%$ and $90 \%$ concentrations on aflatoxins (AFs) pro-ducion by A. flavus and A. parasiticus.

\begin{tabular}{|c|c|c|c|c|c|c|c|}
\hline & Aflatoxins & A.fla & vus & A. $p$ & rasiticus & & \\
\hline $\begin{array}{r}\text { Honey } \\
(\%)\end{array}$ & onc. & AFB1 & AFB2 & AFB1 & AFB2 & AFG1 & AFG2 \\
\hline & $70 \%$ & 22.6 & 19.5 & 18.2 & 31.5 & 14.0 & 19.3 \\
\hline 它 & $80 \%$ & 8.3 & 4.4 & 6.5 & 5.2 & 8.1 & 5.3 \\
\hline 量 & $90 \%$ & 2.9 & 3.2 & 4.2 & 3.9 & 4.6 & 3.7 \\
\hline & $70 \%$ & 10.2 & 7.0 & 21.0 & 17.2 & 19.4 & 9.6 \\
\hline 远 & $80 \%$ & 7.4 & 5.3 & 13.0 & 10.4 & 6.2 & 3.1 \\
\hline$\frac{1}{2}$ & $90 \%$ & 3.6 & 5.2 & 1.2 & 2.0 & 3.4 & 2.9 \\
\hline & $70 \%$ & 11.2 & 14.0 & 16.0 & 14.0 & 21.3 & 12.3 \\
\hline$\stackrel{\tilde{g}}{\Xi}$ & $80 \%$ & 7.4 & 5.6 & 5.0 & 3.2 & 10.0 & 14.6 \\
\hline$\sum^{0} \underline{\theta}$ & $90 \%$ & 2.8 & 4.0 & 2.1 & 2.6 & 3.8 & 2.4 \\
\hline Stanc & $r d s$ & 86.5 & 87.0 & 86.5 & 87.0 & 88.3 & 86.2 \\
\hline
\end{tabular}

The present results are on line with those reported by Wellford et al (2005) who suggested that substituting sugar with honey in processed food can inhibit the harmful and genotoxic effects of mycotoxins, aflatoxins $B_{1}, B_{2}, G_{1}$ and $G_{2}$ production which was increased in medium containing $32 \%$ honey but decreased in medium of high honey concentration with no production of aflatoxin $B_{2}$ and $\mathrm{G}_{2}$. Generally researchers did not find any positive relationship between A. parasiticus mycel-ium weight and mycotoxins production.

Hermínia et al (2003) declared that A. flavus was highly affected by honey used the percentage of growth were determinated by $(57.5 \%)$, followed by $A$. 


\section{Amal A.I. Mekawey}

niger (51.3\%), A. fumigatus (45.0\%) and A. candidus $(28.7 \%)$. Penicillium spp. and Mucor sp. were present in 38.8 and $31.3 \%$ respectively. Saccharomyces sp. and Candida humicola had high incidence (88.8 and $75.0 \%$ respectively). None of samples revealed to be contaminated with aflatoxins. Also, El-Arab et al (2006) concluded that no aflatoxins detected in all samples used by all tested honey marketed in Jeddah, Saudi Arabia.

Conclusively, the uses of natural products as drugs are crucial instead of the synthetic com-pounds, which possess sever toxicity and side ef-fects besides being very expensive. Hence, the use of natural products represents a valuable solu-tion. This study conveys the se of Egyptian hon- eys as a helper in the therapy or the control of the aflatoxins produced by fungi which caused serious diseases of liver such as hepatic necrosis, cirrhosis, and/or carcinoma. Moreover, it can be used in the treatment of various pathogenic bacte-rial and fungal diseases. The antiviral activity and antitumor of Egyptian honeys, their chenical analysis and mode of actions will be investigated in a further study.
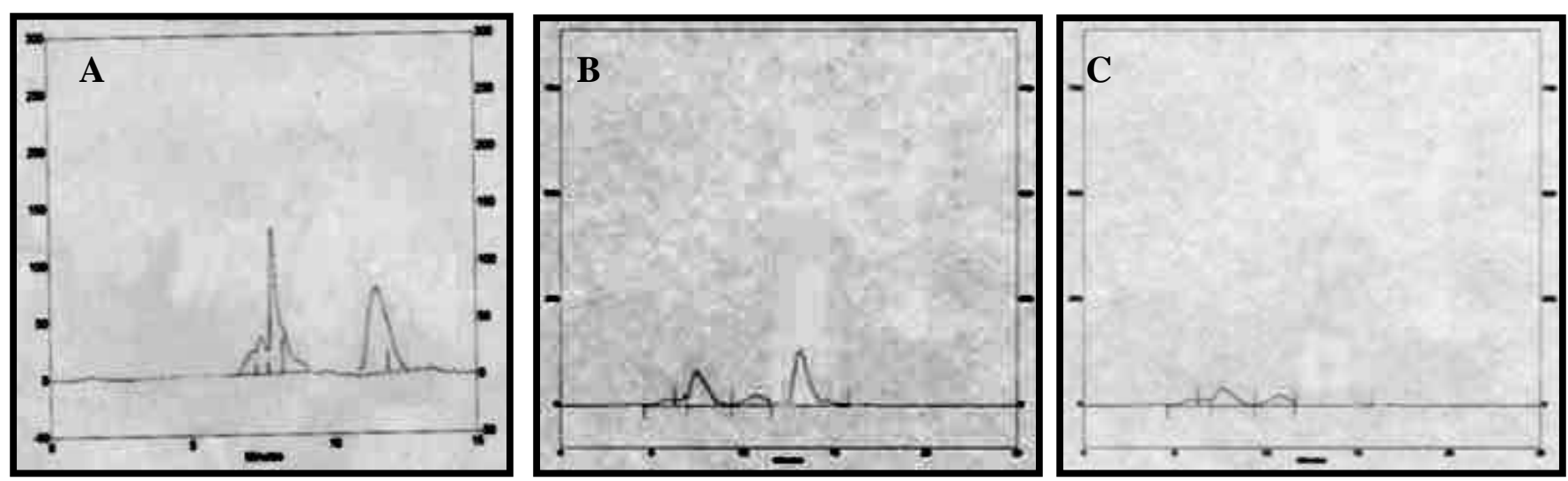

Fig. 2. Photographic showed the effect of mountain honey on aflatoxins (AFB1 and AFB2) produced by A. flavus at (A) $70 \%$; (B) $80 \%$ and (C) $90 \%$ concentrations
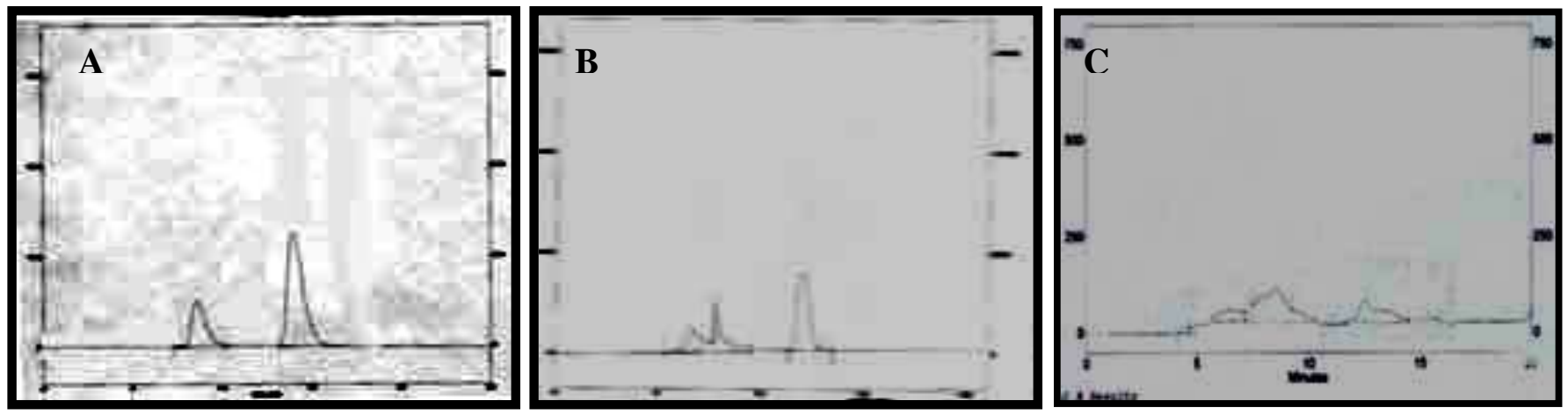

Fig. 3. Photographic showed the effect of nuwara clover honey on aflatoxins (AFB1 and AFB2) produced by A. flavus at (A) $70 \%$; (B) $80 \%$ and (C) $90 \%$ concentrations 
Evaluation the inhibitory action of Egyptian honey from various sources on fungal and bacterial growth and aflatoxins production
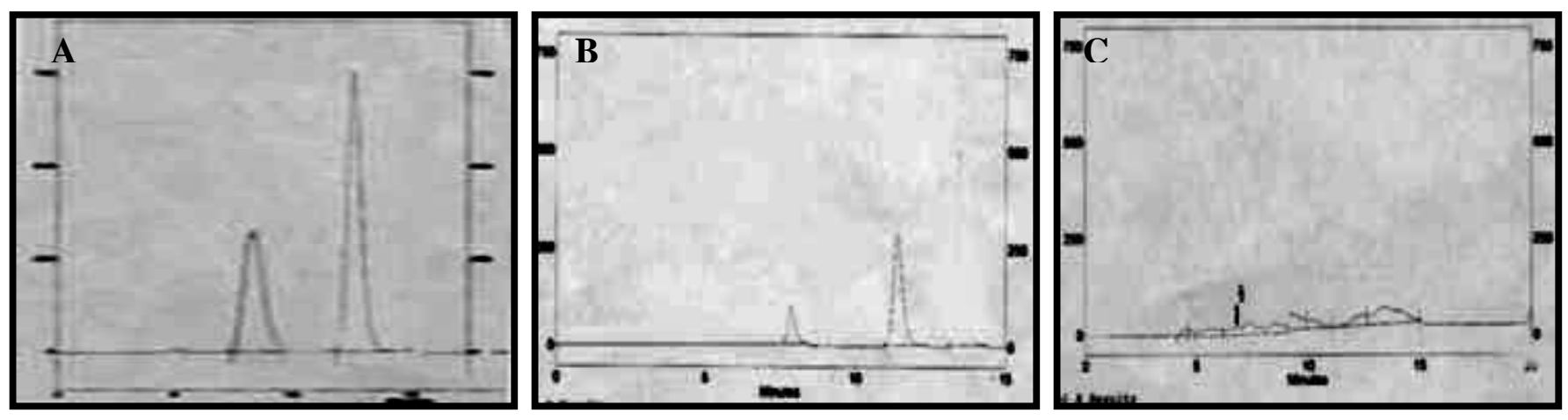

Fig. 4. Photographic showed the effect of citrus honey on aflatoxins (AFB1 and AFB2) produced by A. flavus at (A) $70 \%$; (B) $80 \%$ and (C) $90 \%$ concentrations
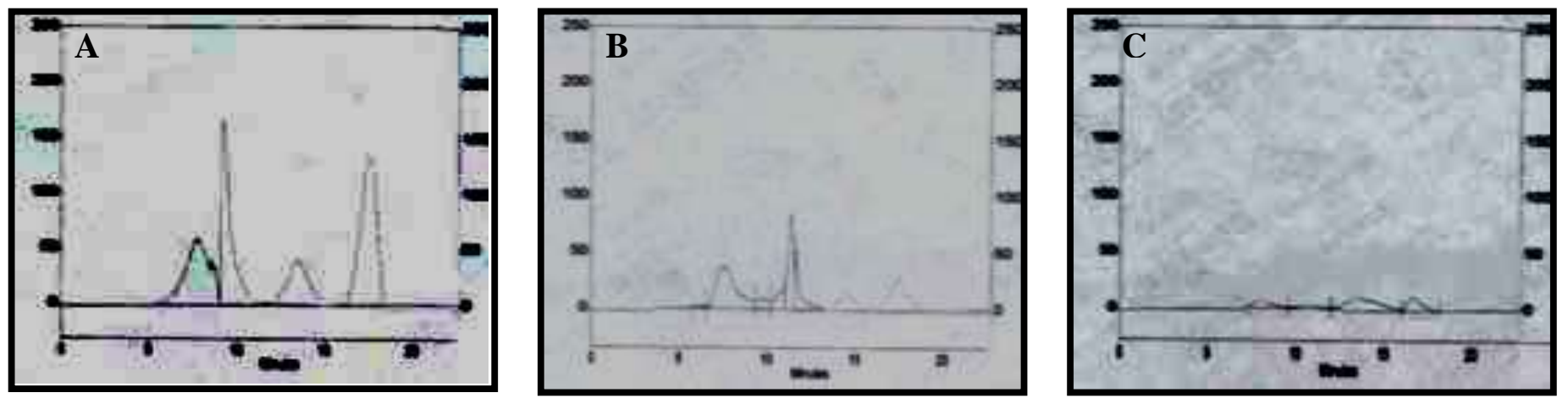

Fig. 6. Photographic showed the effect of nuwara clover honey on aflatoxins (AFB1; AFB2; AFG1 and AFG2) produced by A. parasiticus at (A) $70 \%$; (B) $80 \%$ and (C) $90 \%$ concentrations
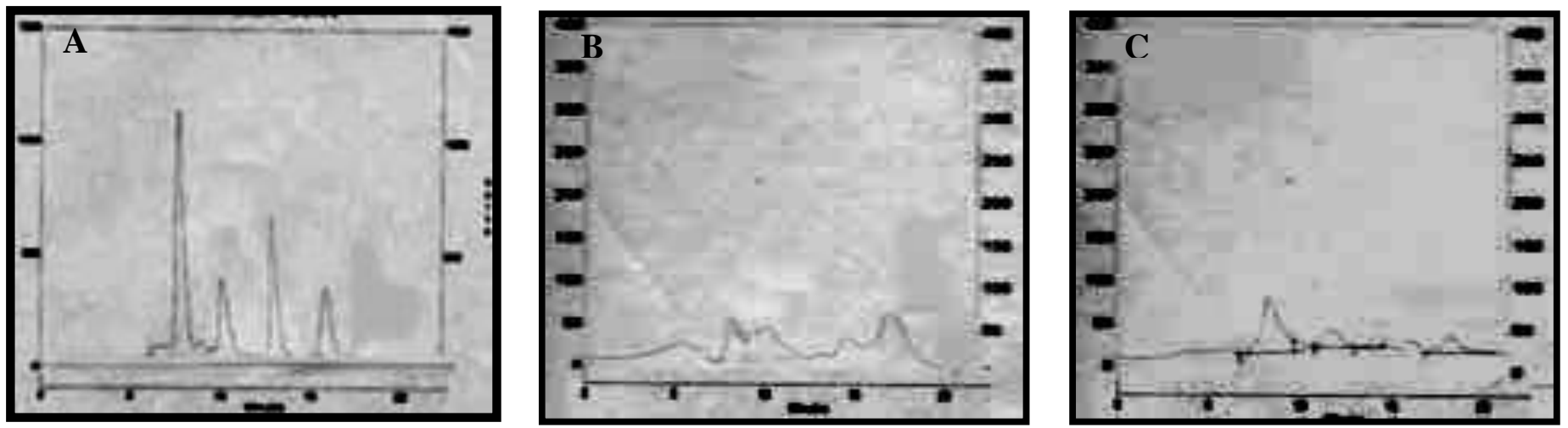

Fig. 7. Photographic showed the effect of citrus honey on aflatoxins (AFB1; AFB2; AFG1 and AFG2) produced by A. parasiticus at (A) $70 \%$; (B) $80 \%$ and (C) $90 \%$ concentrations

\section{REFERENCES}

Abdel-Kader, H.A. and S.R. Seddkey (1995). In vitro study of the effect of some medicinal plants on the growth of some dermatophytes. Assiut Vet.. Med. J., 34: 67 - 72.

Accinelli, C.; H.K. Abbas; R.M. Zablotowicz and J.R. Wilkinson (2008). Aspergillus flavus aflatoxin occurrence and expression of aflatoxin biosynthesis genes in soil. Can. J. Microbiol. 54(5): 371-379.

Atlas, R.M. (1993). Handbook of Microbilology Media. P. 278, 538\&785. In: Laurence, C. and Parks, L.C. eds. CRC Press, New York. 
Amal A.I. Mekawey

Bang, L.M.; C. Buntting, and P. Molan, (2003). The effect of dilution on the rate of hydrogen peroxide production in honey and its implica-tions for wound healing. J. Altern. Comple-ment Med. 9: 267273

Basson, N.J.; I. J. Toit, and S. R. Grobler (2008). Antibacterial action of honey on oral strepto-cocci. J. Dent. Assoc. Afr. 49: 339-341.

Brady, N.; P. Molan and L. Bang, (2004). A sur-vey of non-manuka New Zealand honeys for antibacterial and antifungal activities. Journal of Apicultural Research 43 (2): 47 52.

Cooper, R. A.; P. C. Molan and K. G. Harding (1999). Antibacterial activity of honey against strains of Staphylococcus aureus from infected wounds. Journal of Royal Society of f Medicine 92: 283 285.

Efem, S.E. (1988): Clinical observations on the wound healing properties of honey. Br. J. Surg. 75: 679-681.

El-Arab, A. M. E.; M .G. Shenouda; E. M. Hegazy and B. A. Azzat (2006). Effect of dietary honey on intestinal microflora and toxicity offf mycotoxins in mice. BMC Complementayy and Alternative Medicine 6: $30-38$.

Hermínia, M.M.; M.L. Martins and A. Bernardo (2003). Bacillaceae spores, fungi and aflato-xins determination in honey. Revista Portu-guesa de Ciencias Veterinárias (RPCV) 98 (546): 8588.

Ijaz, T. F.; M.K. Ranjha; M.A. Shahzad; M. Khan; N. Imran and S. Ijaz (2008). Antibacterial and antifungal activity of different honeys. International Journal of Infectious Diseases 12 (1): 403 410.

Irish, J.; A. Dee; S. Tahereh and E. B. Shona (2006). Honey has an antifungal effect against Candida species. Medical Mycology 44(3): 289-291.

Kwakman, P.H.; V. J.P. Akker; H. Aslami and S.A. Zaat (2008). Medicalgrade honey kills antibioticresistant bacteria in vitro and eradicates skin colonization. Clin. Infect. Dis. 46(11):1677-1682.

Mekky, T. M. (2007). Effect of crude honey on stability of aflatoxins and growth of Aspergillus flavus. New Egyptian Journal of Microbiology 17: 108-119.

Molan, P.C. (2006). The evidence supporting the use of honey as a wound dressing. Interna tional Journal of Low Extrem Wounds 5:40-54.

Muli, E. M; J. M. Maingi and J. Macharia (2008). Antimicrobial properties of propolis and honey from the Kenyan stingless bee, Dactylurina Schimidti. APIACTA 43: 49-61.

Peterson, S.; K. Steinmeyer and D.L. Eaton (2006). Apiaceous vegetable constituents in-hibit human cytochrome P-450 1A2 (hCYP1A2) activity and hCYP1A2-mediated mutagenicity of aflatoxin B1. Food Chem. Toxicol. 44 (9): 1474-1484.

Stroka, J.; E. Anklam and J. Gilbert (2000). Im-munoaffinity column cleanup with liquid chromatography using post-column bromine-tion for determination of aflatoxins in peanut butter, pistachio paste, fig paste, and paprika powder: collaborative study. J.A.O.A.C.Int. 83: 320-340.

Subrahmanyam, M. (1991). Topical application of honey in treatment of burns. Br. J. Surg. 78:497-498.

Ugur, A.; M. Barlas; N. Ceyhan and V. Turkmen (2000). Antimicrobial effects of propolis extracts on Escherichia coli and Staphylococcus aureus strains resistant to various antibiotics and 
Evaluation the inhibitory action of Egyptian honey from various sources on fungal and bacterial growth and aflatoxins production

some microorganisms. Journal of Medicinal Food 3(4):173-180.

Wahdan, H.A. (1998). Causes of the antimi-robial activity of honey. Infection 26(1): 26-31.
Wellford, T. E.; T. Eadie and G. C. Llewellyn (2005). Evaluation the inhibitory action of honey on fungal growth sporulation, in aflatoxin production. Z. Lebensm Unters Fors-ch. 28 (166): 280-283.

تقييم التأثير المثبط للعسل المصري من مصادر مختلفة على نمو الفطريات والبكتريا و إنتاج الأفلاتوكسين

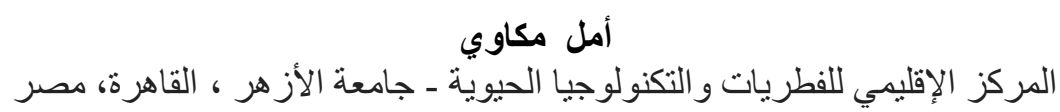

المستخلص (لهالج

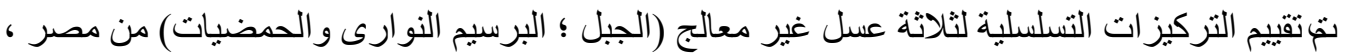

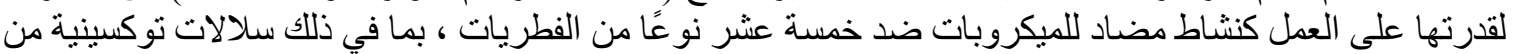

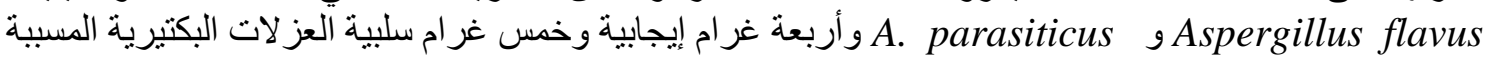

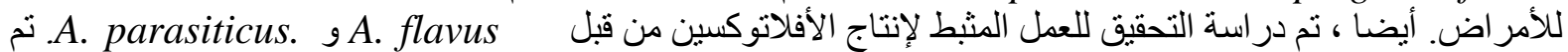
در اسة تركيزات 90 و ٪ و 100 ٪ من الثلاثة انو اع من العسل التى تم تجميعها وقد أظهرت قدرة عالية على منع نمو معظم العز لات الفطرية وات البكتيرية .

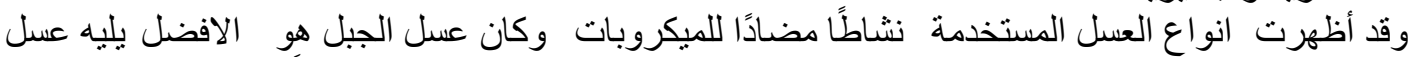

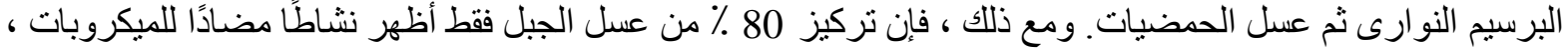

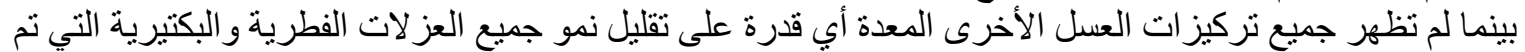

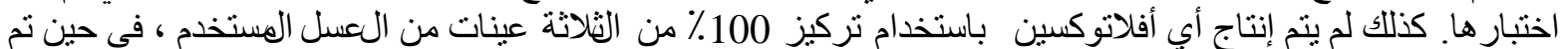

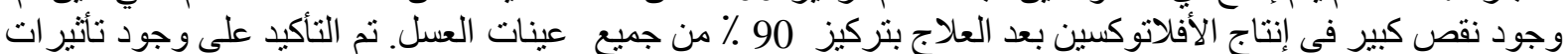

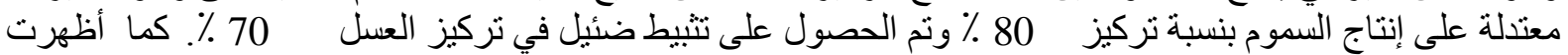

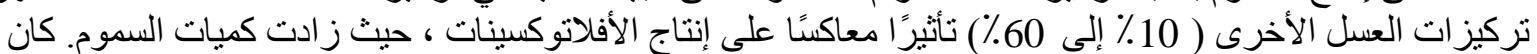

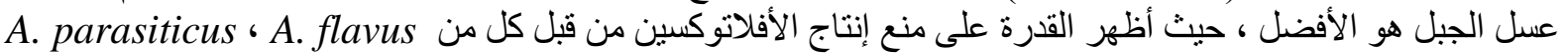
متبو عًا بعسل برسيم الو ارى ثم عسل الحمضيات. 